\title{
LA RESPONSABILIDAD SOCIAL DE LA EMPRESA Y EL DERECHO DE LA COMPETENCIA EN COLOMBIA: UNA VISIÓN DESDE LA ECONOMÍA SOCIAL DE MERCADO Y LA MULTI-STAKEHOLDER THEORY*
}

\author{
The corporate social responsibility and the right of competition \\ in Colombia: A vision from the social economy of the market \\ and the multi-stakeholder theory
}

Wilson Iván Morgestein- Sánchez***

Recepción: 19 de octubre de 2018. Aceptación: 23 de febrero de 2019.

DOI: http://dx.doi.org/10.21017/Rev.Repub.2019.v27.a67

\section{RESUMEN}

El objeto del presente trabajo es el de determinar si una de las responsabilidades que se deriva del ejercicio del derecho a la libertad de competencia, consagrado en el artículo 333 de la Constitución Política de Colombia, es una responsabilidad social por parte de quienes ejercen una actividad económica organizada para con los distintos grupos de interés a los cuales impacta el desarrollo de la empresa. Para resolver la anterior cuestión, se iniciará revisando el concepto de Responsabilidad Social Empresarial y los distintos enfoques desde los cuales se ha abordado. Luego, se estudiarán los aportes que, especialmente la jurisprudencia constitucional colombiana, ha hecho en torno a las instituciones de la economía social de mercado y el derecho a la libertad de competencia, para así poder demostrar cómo la Responsabilidad Social del Empresario que concurre al mercado de bienes y servicios se puede medir teniendo en cuenta los efectos que el desarrollo de su actividad económica tiene sobre todos los grupos de intereses afectados por la misma.

* Artículo de reflexión académica, resultado de «El Derecho de la Competencia y la protección al consumidor», proyecto de investigación con vigencia 2018-2019, y en el cual el autor del presente trabajo académico participa como investigador principal. Este escrito se elaboró en la línea de investigación Teoría del Derecho, de la Política y de la Justicia de la Facultad de Derecho de la Universidad La Gran Colombia, institución que se encargó de financiar esta investigación.

** Magíster en Derecho Comercial de la Universidad Externado de Colombia. Profesorinvestigador de la Facultad de Derecho de la Universidad La Gran Colombia (Bogotá, Colombia), adjunto a la línea de investigación Teoría del Derecho, de la Política y de la Justicia. Correo electrónico Wilson.morgestein@ugc.edu.co 
Palabras clave: Responsabilidad social empresarial, economía social de mercado, libertad de competencia, Multi - Stakeholder Theory.

\begin{abstract}
The purpose of this paper is to determine if one of the responsibilities arising from the exercise of the right to freedom of competition, enshrined in Article 333 of the Political Constitution of Colombia, is a social responsibility on the part of those who exercise an activity economic organized for the different interest groups to which the development of the company impacts. To resolve the above issue, it will begin by reviewing the concept of Corporate Social Responsibility and the different approaches from which it has been addressed. Then, the contributions that, especially Colombian constitutional jurisprudence, has made around the institutions of the social market economy and the right to freedom of competition will be studied, in order to demonstrate how the Social Responsibility of the Entrepreneur who attends the market of goods and services can be measured taking into account the effects that the development of its economic activity has on all interest groups affected by it.
\end{abstract}

Key words: Corporate Social Responsibility, Social Market Economy, Freedom of Competition, Multi - Stakeholder Theory.

\title{
INTRODUCCIÓN
}

Las tendencias contemporáneas en materia de Responsabilidad Social de la Empresa apuntan a una fusión entre los principios propios de la escuela económica o liberal y los postulados de la escuela social y, en consecuencia, admiten que el empresario puede hacer efectivo su legítimo derecho de maximizar sus ganancias patrimoniales, pero al mismo tiempo debe atender los intereses de los diversos grupos de sujetos que se ven impactados por el desarrollo de su actividad económica.

Por otra parte, y al tenor de la disposición contenida en el inciso $2 .^{\circ}$ del artículo 333 de la Constitución Nacional, «La libre competencia económica es un derecho de todos que supone responsabilidades». Esta norma se erige como una expresión de la economía social de mercado, modelo económico adoptado por el Constituyente de 1991, y el cual se presenta como una simbiosis del liberalismo económico clásico y las modalidades de economía de planificación centralizada.

Así las cosas, cabe preguntarse si una de las responsabilidades que se derivan del ejercicio del derecho a la libertad de competencia es una responsabilidad social 
por parte de quienes ejercen una actividad económica organizada para con los distintos grupos de intereses a los cuales impacta el desarrollo de la empresa; y si la respuesta resultare afirmativa, se demostraría la conexión que existe entre los conceptos de Responsabilidad Social Empresarial -de estirpe esencialmente económica -, y el derecho a la libertad competencia, en la forma en que fue concebido y consagrado en la actual Constitución Política de Colombia.

Por lo demás, se considera que la «multi-stakeholder theory» es la metodología más adecuada para determinar si el empresario que concurre el mercado de bienes y servicios está siendo socialmente responsable, en la medida en que este método mide los efectos que el desarrollo de la empresa tiene sobre los diversos grupos de intereses afectados por la misma.

\section{METODOLOGÍA}

Teniendo presente que el objetivo de la investigación es el de establecer si una de las responsabilidades que se deriva del ejercicio del derecho a la libertad de competencia, consagrado en el artículo 333 de la Constitución Política de Colombia, es una responsabilidad social por parte de quienes ejercen una actividad económica organizada para con los distintos grupos de interés a los cuales impacta el desarrollo de la empresa, el tipo de investigación que se empleará será el teórico de análisis-síntesis, para lo cual se hará uso de un enfoque básicamente cualitativo. De conformidad con lo expuesto, se iniciará revisando el concepto de Responsabilidad Social Empresarial y los distintos enfoques desde los cuales se ha abordado. Luego, se estudiarán los aportes que ha hecho especialmente la jurisprudencia constitucional colombiana en torno a la instituciones de la economía social de mercado y el derecho a la libertad de competencia, para así poder demostrar cómo la Responsabilidad Social del Empresario que concurre al mercado de bienes y servicios se puede medir teniendo en cuenta los efectos que el desarrollo de su actividad económica tiene sobre todos los grupos de intereses afectados por la misma.

\section{DISCUSIÓN JURÍDICA Y RESULTADOS}

\section{El concepto de Responsabilidad Social de la Empresa}

\subsection{La noción de RSE}

Son diversas las definiciones que del concepto de Responsabilidad Social Empresarial se han construido por parte de los autores vernáculos; por ejemplo, Palma (2009, p. 58) sostiene: 
Esto es lo que conocemos como responsabilidad social empresarial, valga decir, el rol que la empresa tiene para con la sociedad que va más allá de la mera producción y comercialización de bienes y servicios, sino que también implica el asumir compromisos con los grupos de interés para solucionar problemas de la sociedad.

Para Restrepo (2008, p. 3), el concepto se traduce, en primera instancia, en una herramienta a través de la cual las empresas pueden plasmar su voluntad de contemplar otros compromisos distintos al que tienen con los socios y/o accionistas, en el sentido de maximizar los beneficios económicos de estos últimos.

Por su parte, D’Andreis (2015, p. 197) afirma:

Significa que la empresa debe ser responsable ante la sociedad, que su actuación debe ser coherente con los valores fundamentales, con las normas y con los principios desarrollados en la misión y visión de la empresa, para así alcanzar una mayor acogida con la sociedad, y permitir una mejor adaptación a los distintos entornos en condiciones que suponen respetar los derechos reconocidos por la sociedad y los valores que esta comparte.

Pero bien se puede afirmar que la Responsabilidad Social Empresarial hace referencia tanto a una serie de exigencias que la sociedad contemporánea le hace a los núcleos empresariales, como a la respuesta que estos últimos tienen no solo frente a esos requerimientos sino también frente a las implicaciones sociales de sus acciones, y que envuelven temas tales como derechos humanos, medio ambiente, derechos laborales y ética empresarial, entre otros ${ }^{1}$ (Morgestein, 2013, p. 120).

\subsection{Enfoques del concepto de RSE}

En el mundo occidental el problema de la Responsabilidad Social de las Empresas ha sido observado desde dos corrientes principales: la económica (también llamada liberal) y la social; es decir, la discusión se ha dado entre quienes abogan por una mínima intervención del Estado en la economía y la defensa de los mecanismos del libre mercado, y aquellos que asignan a la empresa una función social, cuyo cumplimiento redundaría en mejores condiciones

1. D’Andreis (2015, p. 196): Cada vez más, los clientes y la sociedad en general esperan e incluso exigen, que las empresas jueguen un rol importante en el desarrollo y aumento de la calidad de vida de sus trabajadores, de su comunidad y del país, reconociendo las políticas y prácticas corporativas socialmente responsables, actuando de manera ética, lo cual constituye a la final una estrategia comercial que las empresas líderes transforman en una ventaja competitiva. 
económicas, sociales y hasta culturales para la colectividad (Yepes et al., 2007, p. 109).

Frente a la primera corriente, es decir, la económica o liberal, se puede afirmar que su principal defensor fue el profesor de la Universidad de Chicago y premio Nóbel de Economía, Milton Friedman, quien catalogó de subversiva la teoría de la Responsabilidad Social Empresarial, como quiera que esta se opone no solo al principal sino al único fin de las empresas que es el de maximizar los rendimientos económicos de sus asociados, de manera tal que si la empresa cumple con este propósito, pues estará siendo responsable, porque en la medida en que los recursos de las corporaciones sean utilizados con eficiencia económica, se generarán beneficios para la sociedad como oferta de empleo, productividad e inversión, sin que sea necesario que los órganos de administración del núcleo empresarial tengan que implementar programas ni destinar recursos para resolver problemas sociales; es más, esa asignación de recursos con fines de solidaridad está prohibida, porque se considera injusto el desvío de dineros que pertenecen única y exclusivamente a los asociados de la corporación (Morgestein, 2013, p. 121) 2 .

En cuanto a la segunda corriente mencionada, es decir, la social, la misma rechaza de plano la afirmación de que la única obligación de las empresas es la de incrementar las utilidades financieras de los asociados en la corporación que desarrolla la actividad económica; por el contrario, esta teoría endilga a la empresa una responsabilidad para con la sociedad (Yepes et al., 2007, pp. 111$112)^{3}$.

2. Como se puede ver, la tesis de Friedman tiene como fundamento la teoría de la «mano invisible» de Adam Smith, ya que de una u otra forma sostiene que nada garantiza mejor el bienestar general que la libre interacción de agentes privados en un mercado igualmente libre o, dicho de otra forma, la mejor manera de incrementar el bienestar de la comunidad es permitiendo que el mercado funcione libremente, sin que sea dada ninguna intervención del Estado en la economía (Yepes et al., 2001, pp. 109-110 y 116-117).

3. Merrick Dodd, profesor de la Universidad de Harvard, afirmó que los gerentes tienen responsabilidades, no solo ante los dueños de la firma, sino ante la sociedad en general, porque «es la sociedad la fuente de los beneficios que obtienen los dueños de la gran firma moderna, incentivada principalmente por la legislación». El planteamiento del mencionado profesor resultó abiertamente opuesto al de Adolf A. Berle, catedrático de la Universidad de Columbia, quien sostuvo que los gerentes son responsables únicamente ante los accionistas de la firma (Jiménez, 2008, p. 5). Otro destacado exponente de la corriente social de la Responsabilidad Corporativa es el sociólogo Daniel Bell, quien predica de la empresa una naturaleza social, porque la misma se debe a la comunidad, de manera tal que en su planeación y ejecución no solo debe contemplar la satisfacción de los intereses patrimoniales de socios y/o accionistas, sino las expectativas y necesidades de todos los grupos presentes en el conglomerado social en el cual se desarrolla, 
Ahora bien, las distintas visiones que de una u otra forma encajan dentro de la corriente social de la Responsabilidad Empresaria se caracterizan por afirmar que las obligaciones y cargas de la empresa no se circunscriben única y exclusivamente a sus asociados, sino que, por el contrario, el núcleo empresarial tiene responsabilidades con los distintos grupos de interés o stakeholders que directa o indirectamente se ven afectados por el desarrollo de la actividad económica, de manera tal que la noción de stakeholders es fundamental para determinar quiénes pueden reclamar responsabilidades de la empresa (Morgestein, 2013, p. 123).

\subsection{La teoría de los stakeholders y una visión ecléctica del concepto de RSE}

La teoría de los stakeholders fue propuesta por el filósofo norteamericano y profesor de administración de negocios, Edward Freeman, quien presenta a la empresa como un sistema relacionado de un modo concreto con la sociedad, a través de grupos de interés que pueden tener un impacto directo o indirecto en la empresa, como también pueden recibir influencia de la misma, lo que lleva a que los intereses de todos los stakeholders deban estar incorporados en los intereses de la empresa (Yepes et al., 2007, pp. 128-129) ${ }^{4}$.

Por su parte, afirma D’Andreis (2015, p. 200):

Es importante reconocer que existen públicos o actores con los que toda empresa se interrelaciona. A estos se les llama "públicos interesados" que son todas aquellas personas a quienes el negocio afecta y se ven impactados por la empresa de manera negativa o positiva. La empresa puede orientar sus prácticas responsables hacia el interior de la empresa o hacia fuera de ella. En cada caso, ya sea interno o externo, existen diferentes públicos interesados hacia donde puede focalizar su acción. Algunos públicos interesados están a lo interno de la empresa, como son los colaboradores, accionistas, y la alta gerencia, por ejemplo. Al otro externo de la empresa, se encuentran los proveedores, los clientes, y la comunidad en general.

Pero de lo hasta ahora expuesto, con relación a las visiones de la Responsabilidad Social Empresarial, se puede concluir que una corriente no excluye la otra;

porque, en últimas, estos diversos grupos de interés son los verdaderos dueños de la empresa, y no los asociados que aportan su capital para el desarrollo de la misma (Morgestein, 2013, p. 122).

4. Adela Cortina plantea un enfoque integral del concepto de empresa, en el cual se concilien tanto el aspecto económico como el ético de la misma, que permita acercar al núcleo empresarial a los contextos humanos, precisamente porque la empresa está creada sobre relaciones humanas, lo que trae como consecuencia que ella sea responsable frente a todos y cada uno de los implicados en su desarrollo (Yepes et al., 2007, p. 124-132). 
es decir, lo social no excluye lo económico. Es más: tal y como lo pone de presente Restrepo (2008, p. 5), la primera obligación de carácter ético asociada al concepto de responsabilidad social de las empresas es la de gestionar eficientemente el capital que la sociedad les ha confiado: ese es el primer deber; luego, obviamente, la empresa debe asumir sus demás obligaciones sociales (Morgestein, 2013, p. 125)

Ahora, el compromiso de la empresa con sus responsabilidades sociales no es antagónico a su propósito de resultados económicos, ya que «un actuar socialmente responsable» se puede traducir en un aumento en la competitividad actual y futura de la empresa (Yepes, Peña y Sánchez, 2007, p. 52); es decir, es perfectamente posible conciliar los intereses económicos de la empresa con las expectativas de la colectividad en la cual se desarrolla.

Para reforzar y concluir este acápite se hace importante citar a A. B. Carroll (citada por Yepes et al. 2007, p. 128), quien definió la Responsabilidad Social Empresarial en los siguientes términos: «La responsabilidad social de la empresa abarca las expectativas económicas, legales, éticas y filantrópicas de la sociedad, en un momento determinado del tiempo», de manera tal que la Responsabilidad Social se crea asumiendo que cada uno de los componentes de la misma no excluye al otro (Morgestein, 2013, p. 125).

\section{Economía social de mercado y derecho a la libertad de competencia: noción, facultades y límites}

\subsection{La economía social de mercado en la Constitución Política de 1991}

De conformidad con lo sostenido por la Corte Constitucional, la Carta Política de 1991 adoptó el modelo de economía social de mercado ${ }^{6}$, el cual reconoce a

5. Sobre este punto Peter Druker sostiene (citado por Dávila, 1996, p. 17): «El rendimiento económico es la primera responsabilidad de un negocio. El negocio que no muestra utilidades iguales por lo menos al costo de capital es socialmente irresponsable. Desperdicia los recursos de la sociedad. El rendimiento económico es la base. Sin él, un negocio no puede desempeñar ninguna otra responsabilidad, no puede ser un buen empleador, un buen ciudadano, un buen vecino. Pero el rendimiento económico no es la única responsabilidad de un negocio, ni es el rendimiento educativo la única responsabilidad de una escuela, ni el rendimiento en salud la única responsabilidad de un hospital. El poder siempre tiene que equilibrarse con la responsabilidad: de otra manera, expiraría. Pero sin responsabilidad, el poder siempre degenera en no-rendimiento. Y las organizaciones tienen poder aún en cuando solo sea poder social».

6. «en el que el mercado libre desempeña un papel fundamental pero la intervención general del Estado en la economía se establece como piedra angular de la actuación estatal (al considerarse el mecanismo idóneo para corregir falla), propicia el desarrollo 
la libertad económica como motor del desarrollo social, pero también le fija límites a los derechos a la libertad de empresa y de competencia, con el propósito de que el Estado cumpla con fines constitucionalmente valiosos, destinados a la protección del interés general (Colombia, Corte Constitucional, sentencia C-830 de 2010, magistrado ponente Luis Ernesto Vargas Silva).

Ahora bien, la Ley Fundamental colombiana reconoce a la libertad de empresa, la libre iniciativa privada y la libre competencia económica ${ }^{7}$ como garantías para el logro del desarrollo económico y el bienestar general ${ }^{8}$, lo cual concuerda con el concepto de economía social de mercado ${ }^{9}$, el cual se presenta como una simbiosis entre los postulados de dos sistemas económicos considerados antagónicos (Alarcón, 2018, p. 164): el liberalismo económico clásico y las modalidades de economía de planificación centralizada en las que el Estado es el único agente relevante del mercado y la producción de bienes y servicios es un monopolio público (Colombia, Corte Constitucional, sentencia C-228 de 2010, magistrado ponente Luis Ernesto Vargas Silva $)^{10}$.

En efecto, de conformidad con el artículo 333 de la Constitución Nacional:

económico equitativo y garantiza la supremacía del bien común -que en un sistema liberal de mercado no es prioridad-. Bajo este esquema no es posible predicar confianza en la mano invisible del mercado y mucho menos libertad absoluta para que el Estado intervenga en la economía» (Alarcón, 2018, p. 146).

7. Sobre los orígenes de la libertad de competencia, apunta Medina (2018, p. 356): «el liberalismo del siglo XVIII y la Revolución Industrial, aunadas a los conceptos jacobinos de la Revolución Francesa, impusieron rápidamente el principio de la libertad económica y, como lógico corolario, el de la libertad de competencia».

8. En este sentido, afirma Santos (2011, p. 133): «hay que seguir fomentando la libre competencia en el mercado como una forma eficiente de repartir los recursos económicos. La competencia hace que las empresas se esfuercen en ser lo más eficientes posible, reduciendo costes para garantizar que los precios sean los más bajos posibles e incrementando la calidad y variedad de productos ofrecidos a los consumidores. Y desde luego que las empresas deben seguir manteniendo como uno de sus objetivos prioritarios la búsqueda de beneficios empresariales, porque dichos beneficios son fuente generadora de riqueza y de empleo».

9. Para una aproximación a los orígenes de la economía social de mercado, puede verse: Alarcón, A. (2016). La libre competencia económica en el Derecho colombiano: una revisión desde la economía social de mercado y sus implicaciones normativas. Revista Prolegómenos - Derechos y Valores, 2016 (I), 109-124.

10. Sobre este punto, ha dicho la Superintendencia de Industria y Comercio: «Las libertades económicas guardan una intrínseca relación con la libertad del individuo y con un sistema democrático. En tal sentido, puede afirmarse que difícilmente puede prosperar un Estado moderno que no proteja adecuadamente y decididamente las libertades económicas» (Superintendencia de Industria y Comercio, SIC, s. f.). 
La libertad económica y la libre iniciativa privada son libres, dentro de los límites del bien común. Para su ejercicio, nadie podrá exigir permisos previos ni requisitos, sin autorización de la ley.

La libre competencia es un derecho de todos que supone responsabilidades $(\ldots)$

\subsection{El derecho a la libertad de competencia: noción, facultades y límites}

Según la Corte Constitucional, la libertad económica es el género de los derechos económicos, el cual se desarrolla en los derechos a la libertad de empresa ${ }^{11}$ y a la libertad de competencia ${ }^{12}$ (Colombia, Corte Constitucional, sentencia C978 de 2010, magistrado ponente Luis Ernesto Vargas Silva).

Así las cosas, ha dicho el Máximo Órgano de la Jurisdicción Constitucional que la libertad de competencia

acontece cuando un conjunto de empresarios o de sujetos económicos, bien se trate de personas naturales o jurídicas, dentro de un marco normativo y de igualdad de condiciones, ponen sus esfuerzos o recursos a la conquista de un mercado de bienes y servicios en el que operan otros sujetos con intereses similares. Se trata propiamente de la libertad de concurrir al mercado ofreciendo determinados bienes y servicios, en el marco de la regulación y en la ausencia de barreras u obstáculos que impidan el despliegue de la actividad económica lícita que ha sido escogida por el participante ${ }^{13}$

11. «La libertad de empresa es aquella que se le reconoce a los ciudadanos para afectar o destinar bienes de cualquier tipo para la realización de actividades económicas, para la producción e intercambio de bienes y servicios, conforme a las pautas o modelos de organización propias del mundo económico contemporáneo, con el objetivo de obtener beneficios o ganancias» (Colombia, Corte Constitucional, sentencia C-032 de 2017, magistrado ponente Alberto Rojas Ríos).

12. Expone Garrigues (1976, p. 223): «La competencia es el modo natural de manifestarse la libertad económica y la iniciativa del empresario y, en consecuencia, es la base del sistema capitalista. Libertad y competencia se han hecho términos sinónimos».

13. Sobre este punto resultan de singular importancia las reflexiones de Broseta (1978, pp. 106-107), quien sostiene: «Cuando los juristas se han preocupado de formular un concepto de competencia, se han ocupado fundamentalmente de resaltar los presupuestos de la libertad de competencia. Así ha dicho ASCARELLI que la competencia presupone que dos o más empresarios producen o median en un mismo mercado los mismos productos o servicios, olvidando quizá que -como señaló FRANCESCHELLI- para la competencia es indispensable la libertad de los empresarios. Efectivamente, pueden concurrir dos o más empresarios en el mercado habiéndose puesto previamente de acuerdo para eliminar su competitividad (la lucha entre ellos), en cuyo caso no habrá 
(Colombia, Corte Constitucional, sentencia C-032 de 2017, magistrado ponente Alberto Rojas Ríos).

En el mismo sentido, la Corte Constitucional ha establecido que el derecho a la libertad de competencia confiere a su titular tres facultades fundamentales: (i) la oportunidad de concurrir al mercado, (ii) la posibilidad de ofrecer las condiciones y prerrogativas comerciales que considere apropiadas, y (iii) la posibilidad de contratar con cualquier consumidor o usuario, quien ve en el derecho a la libertad de competencia una garantía en virtud de la cual pueden contratar con quien ofrezca las mejores condiciones dentro de los límites legales y, a su vez, se beneficia -en términos de precio y calidad de bienes y servicios, entre otros- de las ventajas propias de una pluralidad de oferentes (Colombia, Corte Constitucional, sentencia C-909 de 2012, magistrado ponente Nilson Pinilla).

Por otra parte, se debe tener en cuenta que el derecho de la libertad de competencia no es absoluto. Adviértase que la disposición contenida en el artículo 333 de nuestra Carta Política prevé que la libre competencia supone responsabilidades, y que como lo ha sostenido reiteradamente la Corte Constitucional, la libertad de competencia no se erige como un derecho fundamental, ya que es reconocida a los particulares por motivos de interés público ${ }^{14}$ (Colombia, Corte Constitucional, sentencia C-197 de 2012, magistrado ponente José Ignacio Pretelt Chaljub). En efecto, ha dicho el Máximo Órgano de la Jurisdicción Constitucional:

se concibe a la libre competencia económica, como un derecho individual y a la vez colectivo (artículo 88 de la Constitución), cuya finalidad es alcanzar un estado de competencia real, libre y no falseada, que permita la obtención

verdadera competencia. Habrá concurrencia, pero no competencia. La competencia es sinónimo de libertad y de lucha. Pensamos que la libertad de competencia presupone necesariamente la presencia de tres requisitos: dos libertades y una igualdad. En primer lugar, la libertad de iniciativa, o de acceso a la actividad económica. En segundo lugar, libertad para determinar las circunstancias y el modo, o forma de su actividad (calidad, modelos, cantidad, producción, etc.). Finalmente, es esencial la igualdad de los competidores ante la Ley. Por ello, cuando de modo absoluto se rompen estos presupuestos constitutivos, puede pensarse que no existe libertad de competencia».

14. Sobre el particular, enseña Galgano (1999, p. 141): «Para la ciencia económica clásica, es un principio fundamental del sistema económico, ya que se confía que varios empresarios que compiten entre ellos tenderán, para obtener la preferencia de los consumidores, a mejorar la calidad de los productos y a reducir los precios; se confía en que ellos tratarán, para superarse mutuamente, de llegar a una utilización más intensa de los recursos naturales y humanos, con el efecto de aumentar cada vez más la prosperidad general». 
del lucro individual para el empresario, a la vez que genera beneficios para el consumidor con bienes y servicios de mejor calidad, con mayores garantías y a un precio real y justo ${ }^{15}$. Por lo tanto, el Estado bajo una concepción social del mercado, no actúa solo como garante de los derechos económicos individuales, sino como corrector de las desigualdades sociales que se derivan del ejercicio irregular o arbitrario de tales libertades ${ }^{16}$. Por ello, la protección a la libre competencia económica tiene también como objeto, la competencia en sí misma considerada, es decir, más allá de salvaguardar la relación o tensión entre competidores, debe impulsar o promover la existencia de una pluralidad de oferentes que hagan efectivo el derecho a la libre elección de los consumidores ${ }^{17}$, y le permita al Estado evitar la conformación de monopolios, las prácticas restrictivas de la competencia o eventuales abusos de posiciones dominantes que produzcan distorsiones en el sistema económico competitivo. Así se garantiza tanto el interés de los competidores, el colectivo de los consumidores y el interés público del Estado (Colombia, Corte Constitucional, sentencia C-228 de 2010, magistrado ponente Luis Ernesto Vargas Silva).

Ahora, un asunto esencial en lo que tiene que ver con la protección del derecho de la libertad de competencia es el de los límites que deben ser impuestos a la libertad económica, ya que se pretende evitar que un uso abusivo de las libertades constitucionales impida el goce efectivo de los derechos vinculados con dichos bienes-valores (Colombia, Corte Constitucional, sentencia C-228 de 2010, magistrado ponente Luis Ernesto Vargas Silva). Pues bien, dichos límites pueden ser de dos clases: (i) los que se imponen los mismos actores del mercado, los cuales se pueden hacer contener, entre otras herramientas, en los «manuales de buenas prácticas», y (ii) los que son impuestos mediante disposición

15. En otra providencia, dijo la Corte Constitucional: «La competencia es un principio estructural de la economía social del mercado, que no solo está orientada a la defensa de los intereses particulares de los empresarios que interactúan en el mercado sino que propende por la protección del interés público, que se materializa en el beneficio obtenido por la comunidad de una mayor calidad y unos mejores precios de los bienes y servicios que se derivan como resultado de una sana concurrencia» (Colombia, Corte Constitucional, sentencia C- 616 de 2001, magistrado ponente Rodrigo Escobar Gil).

16. Por eso sostiene Salazar (2013, p. 147): «la protección de la competencia es un principio de la economía de mercado encaminado a la protección del interés público que se encuentra inmerso en el mercado, y su violación genera efectos negativos tanto en el mercado que se protege, como en el patrimonio de personas particulares».

17. Afirma Miranda (1997, p. 79): «El derecho a la libre competencia económica implica dos aspectos fundamentales: de una parte garantiza la libertad de los competidores para concurrir al mercado en busca de una clientela; y de otra implica la libertad de los consumidores para escoger y adquirir en el mercado, bienes y servicios, que se ofrezcan en condiciones de competencia». 
legal ${ }^{18}$ (Colombia, Corte Constitucional, sentencia C-032 de 2017, magistrado ponente Alberto Rojas Ríos), introduciendo excepciones y restricciones, sin que por ello se pueda sostener que se están menoscabando las libertades fundamentales que garantizan el derecho de la libre competencia, ya que lo que se pretende es preservar valores superiores (Colombia, Corte Constitucional, sentencia C-616 de 2001, magistrado ponente Rodrigo Escobar Gil).

Así, la disposición contenida en el artículo 333 de nuestra Constitución Nacional, el cual erige a la libre competencia como un derecho de todos que supone responsabilidades, y que estriba en los postulados propios del Estado Social de Derecho, debe entenderse y aplicarse sistemáticamente, sin fraccionar sus efectos y evitando que la ejecución de algunos de sus cánones deba construirse sobre el supuesto de dejar otros inaplicados o inútiles (Colombia, Corte Constitucional, sentencia C-398 de 1995, magistrado ponente José Gregorio Hernández Galindo), tales como el artículo 25, el cual erige al trabajo como un derecho y una obligación social de especial protección estatal en todas sus modalidades; el artículo 57, el cual prescribe que la ley podrá establecer los estímulos y los medios para que los trabajadores participen en la gestión de las empresas; el artículo 58, el cual le endilga al Estado la obligación de promover y proteger las formas asociativas y solidarias de propiedad (Colombia, Corte Constitucional, sentencia T-461 de 1994, magistrado ponente José Gregorio Hernández Galindo); y, por supuesto, el artículo 78, el cual establece que la ley regulará el control de calidad de bienes y servicios ofrecidos y prestados a la comunidad, así como la información que deba suministrarse al público en su comercialización.

En consecuencia, bien se puede concluir que el derecho a la libre competencia debe estar orientado a salvaguardar valiosos bienes constitucionales tales como la salubridad, la seguridad pública, el ambiente, los derechos de los consumidores y el patrimonio cultural de la nación, entre otros (Colombia, Corte Constitucional, sentencia C-909 de 2012, magistrado ponente Nilson Pinilla). Así es, tal y como lo ha sostenido la Superintendencia de Industria y Comercio: «la Constitución Política de Colombia fue apropiadamente diseñada al instituir un adecuado equilibrio entre libertades económicas individuales y su relación y transcendencia para el bien común. La economía social de mercado, puede decirse, involucra una visión integral de la economía» (SIC, s. f. $)^{19}$.

18. Dentro de las normas que pretenden garantizar el derecho de la libertad de competencia, encontramos: (i) la Ley 155 de 1959, (ii) la Ley 256 de 1996 y (iii) la Ley 1340 de 2009.

19. Por eso, llega a sostener Rubio (2010, p. 10): «Pero la pobreza no solo se reduce en un mercado competitivo por la ampliación de la posibilidad de acceder a bienes y servicios de primera necesidad, y por tener, en general, precios más bajos que los que existirían en un mercado monopolístico, sino también porque una política eficiente de competencia 


\section{Responsabilidad Social Empresarial y Derecho a la Libertad de Compe- tencia: conexión}

Se puede afirmar que la Constitución Política de 1991, al adoptar el modelo de economía social de mercado, pretendió conciliar la legítima aspiración de maximización de riqueza de los empresarios que desarrollan su actividad en el territorio nacional, con los derechos de otros grupos de personas que se ven afectados por el desarrollo de la actividad económica, tales como consumidores, competidores y trabajadores, entre otros, y ello con el propósito de que el Estado alcance varios de los fines esenciales que le endilga el artículo $2 .^{\circ}$ de la Constitución Nacional, tales como la promoción de la prosperidad general y la participación de todos en la vida económica y cultural de la Nación, como quiera que

el objetivo de garantizar el libre juego competitivo que pretende el Derecho de la Competencia no debe considerarse como un objetivo en sí mismo, sino como un instrumento para la consecución de objetivos de espectro más amplio, como el bienestar social, el reparto y la gestión eficiente de los recursos, o la sostenibilidad medioambiental ${ }^{20}$ (Santos, 2011, pp. 135-136).

En consecuencia, también se puede sostener que, de conformidad con el inciso 2. ${ }^{\circ}$ del artículo 333 de nuestra Ley Fundamental, una de las responsabilidades

favorece el crecimiento económico, al hacer más eficientes los diferentes mercados, lo que contribuye a la reducción de la pobreza. Y decimos que el crecimiento económico ayuda a la reducción de la pobreza puesto que implica, entre otros, un efecto sobre el empleo, al generar mayores puestos de trabajo, así como un aumento en la recaudación de impuestos, y estos, si se utilizan en debida forma, es decir, en servicios e infraestructura a la que tenga acceso la población de menores recursos, implica una disminución de la pobreza».

20. Recuerda Santos (2011, p. 136): «debe recordarse que Adam Smith, el gran defensor del mercado como árbitro de la distribución eficaz de los recursos, el autor de la expresión 'la mano invisible' con la que en los últimos tiempos se ha 'sacralizado' el concepto de 'libertad de mercado', no era un defensor de los postulados neoliberales, sino que por el contrario siempre mantuvo en su discurso el bien común como fin al que las reglas del mercado debían orientarse. En efecto, Adam Smith fue, sobre todo, un filósofo. Fue catedrático de Lógica y de Filosofía Moral, y su primera gran obra se tituló "La teoría de los sentimientos morales". Buena parte del libro "La riqueza de las naciones", en el que introduce el concepto de la 'mano invisible', está basado en las enseñanzas de su profesor, el catedrático de Filosofía Moral, Francis Hutcheson, y en la sección de su asignatura en la que abordaba la temática de la 'moral práctica'. La tesis que Adam Smith defiende es que la conducta económica fundada en el propio interés desencadena a través de la mano invisible del mercado un resultado que no entraba en los planes de cada individuo: el desarrollo económico y la prosperidad general. Ahora bien, el Estado debe tener siempre, según Adam Smith, un marco de acción que impida que los intereses creados de unos pocos pongan en peligro los intereses más amplios de la sociedad». 
que se deriva del ejercicio del derecho a la libertad de competencia es una responsabilidad social por parte de quienes ejercen una actividad económica organizada para con los distintos grupos de interés a los cuales impacta el desarrollo de la empresa.

Así, el empresario que respeta las normas que integran el Derecho de la Competencia actúa de forma responsable con sus proveedores, clientes y competidores, ya que basa su crecimiento económico en ser cada día más competitivo, reduciendo costes, prestando un mejor servicio a sus clientes y mejorando la calidad y variedad de sus bienes y servicios (Santos, 2011, p. 135).

Ahora bien, ¿cómo comprobar que un empresario que compite en el mercado de bienes y servicios está conciliando su legítima aspiración de incrementar sus ganancias patrimoniales con la responsabilidad social que, sin lugar a dudas, le endilga la Carta Política de 1991?

Se considera como la metodología más apropiada la denominada «multistakeholder theory» ${ }^{21}$, según la cual

el comportamiento de las empresas en el mercado tendría que analizarse teniendo en cuenta qué efectos tiene dicho comportamiento sobre todos los grupos de interés afectados, es decir, no solo sobre los consumidores (como sucede en la actualidad), sino también sobre los trabajadores de la empresa, los clientes, los proveedores y los ciudadanos que son sujetos pasivos de dicho comportamiento (Santos, 2011, p. 143) 22.

En el mismo sentido, sostienen Peralta y Méndez (2015, p. 42):

De forma que, el nivel de responsabilidad que recae sobre cada empresa dependerá de su capacidad para afectar positiva o negativamente al grupo

21. Santos (2011, p. 143): «La "multi-stakeholder theory" es una teoría de gestión organizacional que fue expuesta por primera vez por R. Edward Freeman en su libro "Strategic Management: A Stakeholder Approach". La teoría consiste en identificar todos los grupos cuyos intereses se ven afectados por la actividad de una empresa para posteriormente arbitrar los mecanismos necesarios para que la gestión de la empresa tenga en cuenta todos los intereses afectados».

22. Altzelai y Terradillos (2012, p. 8): «En ese sentido, la responsabilidad social de las empresas se extiende a una amplia variedad de partes interesadas que incluye a socios comerciales y proveedores, consumidores, autoridades públicas y organizaciones no gubernamentales defensoras de la comunidad local y del medio ambiente. La empresa no se reconduce al simple binomio empleador/asalariados, sino que se extiende a todos estos agentes». 
de interés sobre el cual se actúe. Lo anterior implica que la medición del grado de RSE de una empresa será diferente dependiendo del grupo de interés que se esté midiendo y variará de una empresa a la otra, aún si se compararan organizaciones que comparten el mismo contexto (mercado, grupos de interés, actividad económica, etc.).

\section{$(\ldots)$}

el grado de responsabilidad de una empresa (sujeto de responsabilidad), dependerá del grupo de interés con respecto del cual se esté relacionando (objeto de responsabilidad), y más específicamente habría que evaluar la posibilidad de afectación con relación a cada persona, grupo de personas o empresa en particular.

Pero es más, un empresario que es socialmente responsable en el ejercicio del derecho a la libertad de competencia reporta diversos beneficios económicos tales como: mayor productividad, lealtad del cliente, acceso a mercados y credibilidad (D’Andreis, 2015, p. 199), dentro de las varias ventajas que genera para un núcleo empresarial el cumplimiento de sus responsabilidades sociales. Por el contrario, si el empresario no cumple con sus obligaciones, o en el desarrollo de su actividad empresarial lesiona los intereses de otros grupos de personas, perderá la confianza del gobierno y del sistema financiero, la aspiración de los consumidores de adquirir sus bienes y/o servicios se verá mermada y las posibilidades de atraer nuevas inversiones se verán ostensiblemente disminuidas (D’Andreis, 2015, p. 198-199).

Pues bien, según Alfaro (citado por Altzelai y Terradillos [2012, p. 12]), el objetivo de las políticas y normas de defensa de la competencia

es la preservación de las condiciones de mercado de forma que obtengan mayor ventaja los oferentes que respondan más eficazmente a la demanda. Esta dinámica beneficia a los consumidores y al conjunto de la economía, lo cual contribuye al bienestar social y al crecimiento económico.

Ahora, para proteger el derecho a la libertad de competencia, el cual se traduce «en la facultad que tienen todos los empresarios de orientar sus esfuerzos, factores empresariales y de producción a la conquista de un mercado, en un marco de igualdad de condiciones» (Colombia, Corte Constitucional, sentencia C-032 de 2017, magistrado ponente Alberto Rojas Ríos), el legislador ha promulgado varios estatutos relacionados con las prácticas comerciales restrictivas, la competencia desleal y la protección de la libre competencia, entre otros elementos. 
Así, la primera norma sobre protección integral del derecho a la libre competencia fue la Ley 155 de 1959, «Por la cual se dictan algunas disposiciones sobre prácticas comerciales restrictivas», y que está integrada por 4 zonas temáticas. La primera contiene los enunciados generales de la ley relacionados con prohibiciones genéricas, la vigilancia especial de algunas empresas, las facilidades de intervención del Estado y la obligación que tienen algunas empresas de rendir informes a la Superintendencia de Industria y Comercio. La segunda parte de la ley establece el régimen de prohibiciones especiales alrededor de la libre competencia, para luego enumerar actos específicos de competencia desleal. La tercera parte de la ley fija reglas de procedimiento para la investigación y sanción de conductas que afecten la libertad de competencia. Finalmente, la cuarta parte introduce algunas precisiones dentro de la cuales se destaca la disposición contenida en el artículo 18, al tenor del cual, «Los acuerdos, convenios $\mathrm{u}$ operaciones prohibidos por esta ley, son absolutamente nulos por objeto ilícito» (Colombia, Corte Constitucional, sentencia C-032 de 2017, magistrado ponente Alberto Rojas Ríos).

El tema específico de la competencia desleal fue desarrollado a través de la Ley 256 de 1996, «Por la cual se dictan normas sobre competencia desleal», y que está integrada por 4 capítulos. El capítulo I fue destinado a las «disposiciones generales», y en él se precisan los ámbitos de aplicación de la ley y su objeto. El capítulo II fue destinado a los actos de competencia desleal; se establece una prohibición general y una serie de prohibiciones especiales. En el capítulo III se establecen dos tipos de acciones derivadas de la competencia desleal: la acción declarativa y de condena, y la acción preventiva o de prohibición. El capítulo IV fijaba las reglas de procedimiento sobre investigación y sanción de las infracciones por competencia desleal, pero fue derogado por el Código General del Proceso (Colombia, Corte Constitucional, sentencia C-032 de 2017, magistrado ponente Alberto Rojas Ríos).

Finalmente, la Ley 1340 de 2009 fue destinada a la protección de la libre competencia. Esta ley está integrada por 6 títulos. El primero contiene las disposiciones generales, la enunciación de las normas que conforman el régimen general de protección de la competencia económica, y el establecimiento de la competencia privativa de la Superintendencia de Industria y Comercio para investigar y sancionar las infracciones a ese régimen. El Título II contiene el régimen de las integraciones empresariales, enunciando las reglas que disponen el control de las mismas. El Título III se denomina prácticas restrictivas de la competencia, y se refiere a tres asuntos puntuales relacionados con las investigaciones a cargo de la Superintendencia de Industria y Comercio, como son el régimen de beneficios por colaboración, el carácter reservado de las investigaciones y el establecimiento de garantías para la terminación anticipada de las investigaciones. El Título IV prevé las reglas de procedimiento que rigen las actuacio- 
nes de la Superintendencia de Industria y Comercio. El texto finaliza con el título VI, que contiene las disposiciones finales (Colombia, Corte Constitucional, sentencia C-032 de 2017, magistrado ponente Alberto Rojas Ríos).

\section{CONCLUSIÓN}

El modelo de economía social de mercado adoptado por la Carta Política de 1991 implica el reconocimiento de los derechos a la libertad de empresa y a la libertad de competencia -expresiones del derecho a la libertad económicacomo motores del desarrollo social. Ahora bien, en lo que tiene que ver con el derecho a la libertad de competencia, sin duda alguna se puede afirmar que no es absoluto, ya que la misma norma de nuestra Constitución Nacional que lo consagra le endilga responsabilidades que se traducen en obligaciones y cargas que el empresario que concurre al mercado de bienes y servicios debe cumplir, con el fin de salvaguardar valiosos bienes constitucionales; propósito que es posible lograr mediante la armonización del legítimo derecho de quien desarrolla una actividad económica de incrementar sus ganancias patrimoniales con los derechos de los otros grupos de personas que se ven impactados por el desarrollo de la actividad empresarial. Así las cosas, bien se puede advertir que el modelo de economía social de mercado, el cual inspira el derecho a la libertad de competencia, consagrado en nuestra Ley Fundamental, coincide con una visión ecléctica del concepto de responsabilidad social empresarial, el cual pretende conciliar los intereses económicos de la empresa con los derechos y las expectativas de la comunidad en la cual se desarrolla. Por lo demás, la «multi-stakeholder theory» se considera como la metodología más apropiada para comprobar si un empresario que compite en el mercado de bienes y servicios está conciliando su legítima aspiración de incrementar sus ganancias patrimoniales con sus responsabilidades sociales, ya que esta teoría propone una medición de la responsabilidad social de la empresa a través de un análisis del comportamiento del empresario sobre todos los grupos de interés afectados por el desarrollo de su actividad económica.

\section{REFERENCIAS}

Alarcón, A. (2016). La libre competencia económica en el Derecho colombiano: una revisión desde la economía social de mercado y sus implicaciones normativas, Revista Prolegómenos-Derechos y Valores, 2016 (I), 109-124.

Alarcón, A. (2018). Economía social de mercado como sistema constitucional económico colombiano. Un análisis a partir de la jurisprudencia de la Corte Constitucional. Estudios constitucionales, 16 (2), 141-182. 
Altzelai, I., y Terradillos, E. (2012). La responsabilidad social empresarial y la competitividad de las empresas a nivel internacional. Especial referencia a los grupos de empresas cooperativas. Oñati Socio-Legal series, 2 (2), 1-23.

Broseta, M. (1978). Manual de Derecho Mercantil, Madrid: Tecnos.

Colombia, Corte Constitucional, sentencia T-461 de 1994, magistrado ponente José Gregorio Hernández Galindo.

Colombia, Corte Constitucional, sentencia C-398 de 1995, magistrado ponente José Gregorio Hernández Galindo.

Colombia, Corte Constitucional, sentencia C-616 de 2001, magistrado ponente Rodrigo Escobar Gil.

Colombia, Corte Constitucional, sentencia C-228 de 2010, magistrado ponente Luis Ernesto Vargas Silva.

Colombia, Corte Constitucional, sentencia C-830 de 2010, magistrado ponente Luis Ernesto Vargas Silva.

Colombia, Corte Constitucional, sentencia C-978 de 2010, magistrado ponente Luis Ernesto Vargas Silva.

Colombia, Corte Constitucional, sentencia C-197 de 2012, magistrado ponente José Ignacio Pretelt Chaljub.

Colombia, Corte Constitucional, sentencia C-909 de 2012, magistrado ponente Nilson Pinilla.

Colombia, Corte Constitucional, sentencia C-032 de 2017, magistrado ponente Alberto Rojas Ríos.

Dávila, A. (1996). La responsabilidad social en la ciencia de la riqueza. En Empresa privada y Responsabilidad Social, Bogotá: Olga Lucía Toro y Germán Rey.

D’Andreis, A. (2015). Competencia desleal: reflexiones desde la ética y la responsabilidad social empresarial. Advocatus, 12 (25), 195-207.

Jiménez, A. (2008). Hacia una práctica gerencial responsable: conceptos, prácticas y perspectivas actuales. Revista de Derecho Privado de la Universidad de los Andes, (40), $1-26$.

Galgano, F. (1999). Derecho Comercial. El empresario, Santafé de Bogotá: Temis.

Garrigues J. (1976). Curso de Derecho Mercantil, Madrid: Imprenta Aguirre. 
Medina, J. (2018). Derecho Comercial. Parte general, Bogotá: Temis.

Miranda, A. (1997). El régimen general de la libre competencia. Características principales. En Formas de control, colaboración, competencia empresarial y propiedad industrial. Tomo II, Bogotá: Cámara de Comercio de Bogotá.

Morgestein, W. (2013). El tema de la responsabilidad social de la empresa colombiana. Verba Iuris, (29), 111-130.

Palma, A. (2009). Solo las empresas éticas y socialmente responsables sobrevivirán. En Empresas colombianas: actualidad y perspectivas, Bogotá: Superintendencia de Sociedades.

Peralta, D. y Méndez, J. (2015). Responsabilidad social y competencia desleal entre las grandes superficies y sus proveedores. Revista de Contaduría de la Universidad de Antioquia, (66), 37-51.

Restrepo, J. (2008). Apuntes sobre la responsabilidad social empresarial. Revista de Derecho Privado de la Universidad de los Andes, (40), 1-10.

Rubio, J. (2010). Derecho de los mercados, Bogotá: Superintendencia de Industria y Comercio-Legis.

Salazar, C. (2013). Algunos apuntes sobre la culpa en la responsabilidad derivada de las prácticas restrictivas de la competencia. Revista digital de Derecho Administrativo de la Universidad Externado de Colombia, (10), 147-160.

Santos, S. (2011). La responsabilidad social corporativa y el fomento a la libre competencia en el mercado: una simbiosis necesaria. Revista española de relaciones internacionales, (3), 130-159.

Superintendencia de Industria y Comercio. (s. f.). Algunos fallos de la Corte Constitucional sobre las libertades económicas. Recuperado de http:/ / www.sic.gov.co/ sites/default/files/files/Proteccion_Competencia/Abogacia_de_la_competencia/2018/ Algunos-fallos-de-la-Corte-Constitucional-14-06.pdf

Yepes, G., Peña, W., y Sánchez, L. (2007). Responsabilidad social empresarial. Fundamentos y aplicación en las organizaciones de hoy. Bogotá. Universidad Externado de Colombia. 
